\title{
RELIABILITY ANALYSIS OF HELICOPTER BLADE ROTOR PLAY BELL 412 USING NORMAL DISTRIBUTION METHOD
}

\author{
Rastra Arif Pradana ${ }^{1}$, Kris Hariyanto ${ }^{2}$, Fajar Khanif R. ${ }^{3}$ \\ Prodi Teknik Penerbangan \\ Sekolah Tinggi Teknologi Adisutjipto Yogyakarta \\ Jalan Janti Blok R Lanud Adisutjipto, Yogyakarta \\ ${ }^{1}$ rastra.pradana@gmail.com, ${ }^{2}$ krishariyanto76@gmail.com, ${ }_{3}^{3}$ fajar.khanif@gmail.com
}

\begin{abstract}
At the beginning of operation, a main rotor blade on helicopter is certainly in the best condition. When it gets older, the main rotor blade condition will decrease because of the presence of bent, material fatigue and human error during operation. Based on the background, it is necessary to identify the level of reliability of main rotor blade on the Bell 412 helicopter using the normal distribution method. The research data were the age of components of main rotor blade on Bell 412 helicopter during 27 years.Based on the analysis of calculation of the reliability level, employing the normal distribution method and using Microsoft Excel, the reliability value (R) of all serial numbers of Bell 412 helicopter main rotor blade was 99\%, which indicates the reliability of the Bell 412 helicopter main rotor blade is very good.
\end{abstract}

Keywords: Reliability, Helicopter, Blade

\section{Pendahuluan}

Helikopter merupakan pesawat udara yang menggunakan sayap putar (rotary wing) untuk menghasilkan gaya angkat (lift). Sudut (blade) pada rotor berputar mengacu pada sumbu vertikal. Gaya aerodinamis pada helikopter dihasilkan oleh gerakan relatif permukaan sayap terhadap udara. Helikopter dengan sayap putarnya dapat menghasilkan gaya angkat bahkan ketika lajunya bernilai nol (hover). Berbeda dengan pesawat sayap tetap (fixed wing) dimana membutuhkan kecepatan tertentu untuk mempertahankan kondisinya tetap berada di udara. Selain itu, helikopter juga mampu terbang secara vertikal, termasuk saat melakukan take-off dan landing. Terbang secara vertikal merupakan karakteristik mendasar dari rotor helikopter [9].Komponen main rotor blade merupakan subkomponen dari suatu sistem di main rotor. Main rotor blade merupakan baling-baling penggerak utama dan poros kendali dari sebuah helikopter yang terletak di bagian atas, rotor blade mempunyai bentuk airfoil yang sudutnya bisa diubah-ubah dan berfungsi untuk menimbulkan gaya angkat dan gaya dorong pada helikopter. Rotor blade melekat pada main rotor dengan bantuan rotor hub [9].Kondisi sebuah main rotor blade pada awal pengoperasian tentunya dalam kondisi yang paling baik. Dengan bertambahnya umur pengoperasian, kondisi main rotor blade tersebut akan menurun. Pada suatu saat main rotor blade tersebut masih berfungsi, tetapi tingkat keandalanya sudah menurun. Misalnya main rotor blade memerlukan waktu yang lebih lama untuk menjalankan proses yang sama. Kondisi tersebut disebut dengan potensi kegagalan main rotor blade. Penyebab kegagalan antara lain dikarenakan adanya bent, material fatigue, serta kesalahan manusia (human error) saat pengoperasian, program perawatan main rotor blade yang kurang efektif, serta kondisi main rotor blade yang terlalu melentur. Tindakan yang bisa dilakukan untuk mengatasi kegagalan yaitu mereplace atau merepair komponen yang fatigue, revisi program perawatan, serta identifikasi kegagalan yang berulang untuk menentukan preventive maintenance dan corrective action yang tepat.Berdasarkan latar belakang tersebut, maka perlu diidentifikasi tingkat keandalan terhadap terjadinya unscheduled removal pada main rotor 
blade helikopter Bell 412 milik Penerbangan Angkatan Darat. Analisa penelitian ini menggunakan metode distribusi normal agar diperoleh analisis tingkat keandalan.

\section{Metodologi Penelitian}

Lokasi penelitian dilakukan di Bengkel Pusat Penerbangan Angakatan Darat, Pangkalan Udara Utama Angkatan Darat Ahmad Yani Semarang, Bengkel Pusat Penerbangan Angkatan Darat merupakan bengkel perawatan helikopter dibawah komando Pusat Penerbangan Angkatan Darat. Dalam penelitian ini, penulis melaksanakan penelitian di Sub Bengkel Pemeriksaan Bell 412 Bengkel Pusat Penerbangan Angkatan Darat.

\subsection{Jenis dan Objek Penelitian}

Penelitian ini termasuk dalam kategori studi kasus, tempat penelitian hanya dipusatkan atau dilakukan di Bengkel Pusat Penerbangan Angkatan Darat yaitu di Sub Bengkel Pemeriksaan Bell 412. Objek penelitian ini adalah pada data usia komponen helikopter Bell 412 dengan kode registrasi HA 5113. Gambar 1 merupakan gambar sesungguhnya helikopter Bell 412 milik Penerbangan Angkatan Darat.

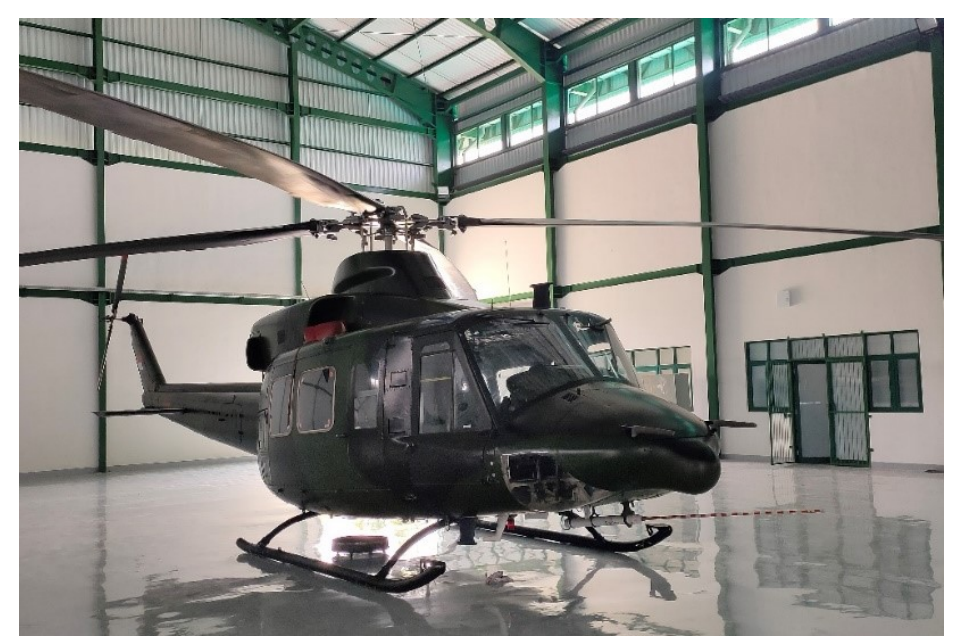

Gambar 1. Helikopter Bell 412 Penerbangan Angkatan Darat

Selanjutnya gambar 2 merupakan gambar sesungguhnya main rotor blade helikopter Bell 412 milik Penerbangan Angkatan Darat.

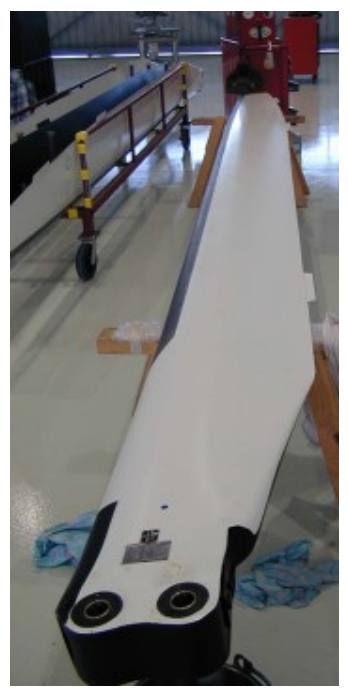

Gambar 2. Main rotor blade Helikopter Bell 412 Penerbangan Angkatan Darat 
Kemudian tabel 1 merupakan data teknis helikopter Bell 412 milik Penerbangan Angkatan Darat.

Tabel 1 Data Teknis Helikopter Bell 412 Penerbangan Angkatan Darat

\begin{tabular}{|c|c|c|}
\hline Exterior & British & SI \\
\hline Height & 11 feet & $3.49 \mathrm{~m}$ \\
\hline Length & 56 feet & $17.11 \mathrm{~m}$ \\
\hline Wide & 9.4 feet & $2.84 \mathrm{~m}$ \\
\hline Wing Span Main Rotor Blade & 46 feet & $14.02 \mathrm{~m}$ \\
\hline \multicolumn{3}{|l|}{ Occupance } \\
\hline Crew & \multicolumn{2}{|c|}{4} \\
\hline Passengers & \multicolumn{2}{|c|}{11} \\
\hline \multicolumn{3}{|l|}{ Operating Weights } \\
\hline Max T/O Weight & $11900 \mathrm{Lb}$ & $5397 \mathrm{Kg}$ \\
\hline Empty Weight & $6400 \mathrm{Lb}$ & $2902 \mathrm{Kg}$ \\
\hline Fuel Capacity & $2200 \mathrm{Lb}$ & $997.9 \mathrm{Kg}$ \\
\hline
\end{tabular}

(Sumber Bell Helicopter, 1993)

\subsection{Metode Penelitian}

Penelitian kuantitatif ini untuk mengetahui tingkat keandalan dari main rotor blade helikopter Bell 412 milik Penerbangan Angkatan Darat. Penelitian keandalan kuantitatif merupakan metode analisis yang dilakukan secara perhitungan matematis. Metode ini dapat dilakukan melalui perolehan data pemeliharaan (maintenance redord) terhadap waktu kegagalan (time to failure) dan waktu perbaikan (time to repair) dari suatu komponen atau sistem. Keandalan dari suatu komponen atau sistem adalah probabilitas untuk tidak mengalami kegagalan atau dapat melaksanakan fungsinya selama periode waktu (t) atau lebih [7]. Dalam penelitian ini dikontrol variabelnya, yaitu hanya mengambil data usia komponen dari bulan Februari tahun 1993 sampai dengan bulan Februari tahun 2020, analisis hanya difokuskan pada helikopter Bell 412 dengan kode registrasi HA 5113, serta tidak melakukan analisis keandalan main rotor blade helikopter Bell 412 dengan serial number A-1614 dikarenakan adanya anomaly product.

\subsection{Pengolahan Data}

Dalam pengolahan data, penulis akan menganalisis tingkat keandalan dari komponen main rotor blade helikopter Bell 412 dalam waktu 27 tahun terakhir (1993-2020). Untuk mengetahui tingkat keandalan dari semua komponen, maka data akan diolah dengan menggunakan software Microsoft Excel.

Reliability atau keandalan didefinisikan sebagai kemampuan dari suatu komponen atau sistem untuk tidak mengalami kegagalan atau dapat melaksanakan fungsinya selama periode waktu $(t)$ yang telah ditentukan. Jadi, keandalan merupakan salah satu aspek yang dapat mempengaruhi kelancaran suatu sistem. Evaluasi keandalan dapat digunakan untuk memperkirakan peluang suatu komponen atau sistem untuk melaksanakan fungsinya dalam jangka waktu dan kondisi operasi tertentu. Keandalan menjadi sangat penting karena akan mempengaruhi profitabilitas suatu perusahaan. Terdapat beberapa hal yang harus diperhatikan dalam evaluasi keandalan, antara lain sebagai berikut : Kegagalan dari komponen maupun sistem harus jelas dan dapat diobservasi, waktu kegagalan dapat diidentifikasi, dan pada saat kondisi nomal performasinya dapat diobservasi [7]. 
Setelah mendapatkan data yang diperlukan di Sub Bengkel Pemeriksaan Bell 412 Bengkel Pusat Penerbangan Angkatan Darat, maka penulis melakukan pengolahan data usia komponen main rotor blade helikopter Bell 412 untuk dianalisis keandalanya. Adapun metode yang digunakan untuk analisis keandalan adalah metode distribusi normal, dengan menggunakan persamaan 2.1 maka bisa diperoleh nilai tingkat keandalanya yang disimbolkan dengan huruf R [7].

$$
R(t)=1-f\left(\frac{t-\mu}{\sigma}\right)
$$

Sebelum mendapatkan nilai tingkat keandalan, harus mendapatkan terlebih dahulu banyaknya kegagalan selama jangka waktu operasi t yang disimbolkan dengan $f(\mathrm{t})$ [7] pada persamaan 2.2.

$$
f(t)=\frac{1}{\sqrt{2 \pi \sigma}} \exp \left[-\frac{1}{2} \frac{(t-\mu)^{2}}{\sigma^{2}}\right]
$$

Sebelum mendapatkan banyaknya kegagalan atau yang disimbolkan dengan $f$ selama jangka operasi waktu t, maka harus mendapatkan terlebih dahulu standar deviasi yang disimbolkan dengan $\sigma_{x}$ yang artinya adalah nilai statistik yang digunakan untuk menentukan bagaimana sebaran data dalam sampel [8]. Berikut persaman 2.3

$$
\sigma_{x}=\sqrt{\frac{\left(\sum_{i=1}^{N} x_{i}^{2}\right)}{N}-\mu_{x}^{2}}
$$

Semua simbol rumus diatas mempunyai arti, sebagai berikut :

$$
\begin{array}{ll}
\mathrm{t} & =\text { Waktu (Variabel) } \\
\mu_{x} & =\text { Mean } \\
\sigma_{\mathrm{x}} & =\text { Standar deviasi } \\
\pi & =\text { Konstanta }=3,14 \\
N & =\text { Banyaknya data } x \\
x_{i} & =\text { Nilai dari data } x
\end{array}
$$

\section{Hasil dan Pembahasan}

Dalam penelitian ini, penulis melakukan analisis tingkat keandalan main rotor blade helikopter Bell 412 dengan menggunakan metode distribusi normal. Hasil dari analisis ini adalah mendapatkan tingkat keandalan komponen main rotor blade helikopter Bell 412 . Perhitungan yang dilakukan penulis menggunakan software Microsoft Excel.

\subsection{Data Usia Komponen Main Rotor Blade helikopter Bell 412}

Data usia komponen main rotor blade helikopter Bell 412 adalah data time since new dan time since overhoul yang berdasarkan laporan dokumen aircraft major component status di Bengkel Pusat Penerbangan Angkatan Darat, nantinya data usia komponen ini akan dianalisis secara kuantitatif menggunkaan metode distribusi normal untuk mencari tingkat keandalan main rotor blade helikopter Bell 412[1][2][3][4][5][6][7]. Tabel 2 merupakan usia komponen time since new dan time since overhoul main rotor blade helikopter Bell 412 yang diperoleh penulis di Sub Bengkel Pemeriksaan Bell 412 Bengkel Pusat Penerbangan Angkatan Darat. 
Tabel 2. Aircraft Major Component Status

\begin{tabular}{|c|c|c|c|c|c|c|c|}
\hline \multirow{4}{*}{\multicolumn{6}{|c|}{ Aircraft Major Component Status }} & A/C Type & :Bell 412 \\
\hline & & & & & & A/C REG & :HA-5113 \\
\hline & & & & & & $\mathbf{A} / \mathbf{C ~ S} / \mathbf{N}$ & :34025 \\
\hline & & & & & & Owner & :TNI-AD \\
\hline \multirow[t]{2}{*}{ NO } & \multirow[t]{2}{*}{ COMPONENT } & \multirow{2}{*}{$\begin{array}{c}\text { SERIAL } \\
\text { NUMBER }\end{array}$} & \multirow[t]{2}{*}{ Doc No } & \multirow[t]{2}{*}{ DATE } & \multirow{2}{*}{$\begin{array}{c}\text { A/C } \\
\text { HOURS }\end{array}$} & \multicolumn{2}{|c|}{ COMP HOURS } \\
\hline & & & & & & TSN & TSO \\
\hline \multirow{2}{*}{$\frac{\mathrm{NO}}{\mathbf{1}}$} & $\begin{array}{c}\text { NAMA } \\
\text { KOMPONEN }\end{array}$ & S.N & Doc & TGL & JAM A.C & \multicolumn{2}{|c|}{ JAM COMP } \\
\hline & 2 & 4 & 5 & 6 & 7 & 8 & 9 \\
\hline 1 & M/R Blade & A-1614 & D/O IPTN & $25-F e b-93$ & 0.00 & 0.00 & 0.00 \\
\hline 2 & M/R Blade & A-1615 & D/O IPTN & 25-Feb-93 & 0.00 & 0.00 & 0.00 \\
\hline 3 & M/R Blade & A-1613 & D/O IPTN & $25-F e b-93$ & 0.00 & 0.00 & 0.00 \\
\hline 4 & M/R Blade & A-1612 & D/O IPTN & $25-F e b-93$ & 0.00 & 0.00 & 0.00 \\
\hline 5 & M/R Blade & A-1622 & SPK 25/IX/2004 & 22-Sep-04 & 2394.50 & 226.43 & \\
\hline 6 & M/R Blade & A-1615 & SPK 25/IX/2004 & 22-Sep-04 & 2394.50 & 2394.50 & \\
\hline 7 & M/R Blade & A-1613 & SPK 25/IX/2004 & 22-Sep-04 & 2394.50 & 2394.50 & \\
\hline 8 & M/R Blade & A-1612 & SPK 25/IX/2004 & 22-Sep-04 & 2394.50 & 2394.50 & \\
\hline 9 & M/R Blade & A-1622 & SPK 12/XI/2012 & 11-Nov-12 & 4159.75 & 3933.32 & 1765.25 \\
\hline 10 & M/R Blade & A-1615 & SPK 12/XI/2012 & 11-Nov-12 & 4159.75 & 4159.75 & 1765.25 \\
\hline 11 & M/R Blade & A-4646 & SPK 12/XI/2012 & 11-Nov-12 & 4159.75 & 0.00 & 0.00 \\
\hline 12 & M/R Blade & A-4633 & SPK 12/XI/2012 & 11-Nov-12 & 4159.75 & 0.00 & 0.00 \\
\hline 13 & M/R Blade & A-1622 & SPK 73/IX/2019 & 19-Feb-20 & 4894.43 & 2499.93 & 2499.93 \\
\hline 14 & M/R Blade & A-1615 & SPK 73/IX/2019 & 19-Feb-20 & 4894.43 & 4894.43 & 2499.93 \\
\hline 15 & M/R Blade & A-4646 & SPK 73/IX/2019 & 19-Feb-20 & 4894.43 & 734.68 & 734.68 \\
\hline 16 & M/R Blade & A-4633 & SPK 73/IX/2019 & 19-Feb-20 & 4894.43 & 734.68 & 734.68 \\
\hline
\end{tabular}

(Sumber Sub Bengkel Pemeriksaan Bell 412 Bengkel Pusat Penerbangan Angkatan Darat)

\subsection{Analisis Keandalan Main Rotor Blade Helikopter Bell 412}

Analisis kuantitatif ini menggunakan metode distribusi normal dikarenakan distribusi normal adalah distribusi yang paling cocok digunakan dalam memodelkan fenomena keausan, dalam perhitunganya menggunakan bantuan software MS Excel. Analisis in bersumber dari data usia komponen time since new dan time since overhoul main rotor blade helikopter Bell 412 milik Penerbangan Angkatan Darat yang ada pada dokumen aircraft major component status. Hasil analisis dan perhitungan data ini menghasilkan output tingkat keandalan komponen main rotor blade helikopter Bell 412 milik Penerbangan Angkatan Darat, yang bida diperoleh nilai tingkat keandalanya yang disimbolkan dengan huruf R. Lebih jelasnya hasil tingkat keandalan main rotor blade helikopter Bell 412 milik Penerbangan Angkatan Darat pada tabel 3 . 
Tabel 3 Hasil Tingkat Keandalan main rotor blade Helikopter Bell 412

\begin{tabular}{|c|c|c|c|}
\hline No & Komponen & Serial Number & Tingkat Keandalan R (t) \\
\hline 1 & $M / R$ Blade & A-1615 & $99 \%$ \\
\hline 2 & $M / R$ Blade & A-1613 & $99 \%$ \\
\hline 3 & $M / R$ Blade & A-1612 & $99 \%$ \\
\hline 4 & $M / R$ Blade & A-1622 & $99 \%$ \\
\hline 5 & $M / R$ Blade & A-4646 & $99 \%$ \\
\hline 6 & $M / R$ Blade & A-4633 & $99 \%$ \\
\hline
\end{tabular}

Dari pengolahan data semua serial number maka didapatkan hasil tingkat keandalan semua serial number adalah $99 \%$ yang mengindikasikan keandalan main rotor blade helikopter Bell 412 milik Penerbangan Angkatan Darat tergolong sangat baik. Serta interval waktu pemeliharaan special inspection yang optimum untuk komponen main rotor blade bell 412 adalah 2500 Hrs yang didapatkan dari maintenance manual Bell 412.

\section{Kesimpulan}

Berdasarkan pembahasan yang telah dilaksanakan diatas, maka dapat diambil kesimpulan yaitu hasil perhitungan tingkat keandalan semua serial number komponen main rotor blade helikopter Bell 412 dengan menggunakan metode distribusi normal adalah 99\% yang mengindikasikan keandalan main rotor blade helikopter Bell 412 milik Penerbangan Angkatan Darat tergolong sangat baik. Serta interval waktu pemeliharaan yang optimum untuk komponen main rotor blade Bell 412 adalah 2500 Hrs yang didapatkan dari maintenance manual.

\section{Daftar Pustaka}

[1] Bell Helicopter. 2013. Maintenance Manual Chapter 4. Textron Company. United States of America

[2] Bell Helicopter. 2013. Maintenance Manual Chapter 5. Textron Company. United States of America

[3] Bell Helicopter. 1993. Maintenance Manual Chapter 6. Textron Company. United States of America

[4] Bell Helicopter. 2009. Maintenance Manual Chapter 18. Textron Company. United States of America

[5] Bell Helicopter. 2009. Maintenance Manual Chapter 62. Textron Company. United States of America

[6] Bell Helicopter. 2013. Component and Repair Overhoul Manual. Textron Company. United States of America.

[7] Ebeling, Charles. 1997. An Introduction Reliability and Maintainibility Engineering. University of Dayton: United States of America

[8] Harinaldi. 2005. Prinsip-prinsip STATISTIK untuk Teknik dan Sains. Penerbit Erlangga: Jakarta

[9] FAA. 2012. Helicopter Flying Handbook: United States of America

[10] https://www.indomiliter.com/nbell-412-sphpep-tulang-punggung-kavaleri-udara-tni$\mathrm{ad} /$ diakses pada hari Selasa, 10 Desember 2019, jam 11.00. 